\title{
Resilient Widowed Older Adults and Their Family and Friend Relations
}

\author{
Hyunsook Kang ${ }^{1, a}$, Bonnie Ahn ${ }^{2, b}$ \\ 1Department of Human Sciences, Human Science Building, RM 129 MSC 168, \\ Texas A\&M University - Kingsville, Kingsville, Texas 78363 - 8202, USA \\ ${ }^{2}$ Department of Counseling \& Human Development, Southeastern Louisiana University, \\ Hammond, LA 70402, USA \\ a,bE-mail address: Hyunsook.Kang@tamu.edu , Bonnie.Ahn@selu.edu
}

\begin{abstract}
This study examined the relationship of family and friends to the resiliency of older widows. Data from the National Social Life, Health, and Aging Project (NSHAP) survey (Waite et al., 2007), which sampled persons $57-85$ years of age $(n=3005)$, was used. It was hypothesized that older widows have greater breadth and depth of family and friend relationships than older married adults. Multiple regression analysis results revealed that older widows engaged more frequently in family and friend relations compared to older married adults, possibly enabling greater resilience to widowhood.
\end{abstract}

Keywords: widowed older adults; resilience; family and friend relations

\section{INTRODUCTION}

\section{Widowed older adults and their family and friend relations}

Currently, the proportion of older adults living alone increases with age. By age 65, almost $50 \%$ of women and $25 \%$ of men live alone due to divorce, death of a spouse, or lifelong single status. By age 85 , about $80 \%$ of women and $43 \%$ of men live alone (U.S. Bureau of the Census, 2012). Although change in marital status is accepted as a normal life experience, the death of a spouse is a significant life event for older adults due to the associated changes in roles, income, identity, housing, social contacts, and physical and emotional health status (Lopata, 1996).

For older adults, transition to widowhood can be an extremely challenging time that requires a tremendous amount of coping. Although a majority of people have the ability to bounce back from general adversity, the ability to demonstrate resilience to widowhood varies greatly based on breadth and depth of family and friend relationships. Even though all widows experience an emotional and physical loss, having frequent contact with family and friends can be the key to a successful show of resilience to such losses. For example, frequent social relationships with relatives and friends may minimize emotional stress and depression while boosting psychological well-being (Lopata, 1996).

Among the multitude of changes that come with widowhood, the most common changes for older widows involve their identity and social relationships, particularly with other couples. Sheykhi (2006) discussed that widowhood removes a central identity as wife or husband. 
Furthermore, older married adults are more likely to socialize with other couples, but when one of the couples experiences widowhood or divorce, disruption in the friendship is likely (Hooyman \& Kiyak, 2010). Utz et al. (2002) proposed that older widows tend to rely on the lifelong relationships from which they derive support and a sense of stability and continuity. Gradually, most older widows modify their social lives to spend less time with married friends and more time with other widowed individuals (Lopata, 1996). Therefore, it is possible to assume that the emotional support provided through rebuilding or intensifying existing relationships with friends and family creates a source of resilience for widows (Bennett, 2005).

Although previous research has found that family support for older adults is important, little data exists about how family and friend relationships can foster resilience for older widows specifically. Given that only a few studies have investigated the topic, mostly with small nonrepresentative samples, there is a need to explore the topic with larger representative samples. The objective of this study is to examine the breadth and depth of relationships with relatives and friends and the possible implications of those relationships with regards to resilience to widowhood.

\section{Theoretical Framework}

Although various theories explain how ties with family and friends foster to widowhood, there is a lack of consensus on the developmental processes of social relations. For example, the convoy model is one of the theories that outlines the developmental process of coping with life changes and the individual, social, cultural, and/or structural factors that serve as determinants of social relations.

\section{Convoy Model}

Kahn and Antonucci (1982) developed the basic concept of the convoy model to explain social relationships and their longitudinal characteristics. The convoy model moves with the individual through time, social circumstance, and each individual's ability to cope with life challenges (Kahn \& Antonucci, 1982). The basic tenet of the convoy model is that social relationships are dynamic in nature; in other words, members of a social network change over time (Kahn \& Antonucci, 1982). Individuals join or leave social networks, move into and out of relationships over the course of their lifetime. Each individual's close social relationships with family and friends may influence their lives positively or negatively (Blieszner, Bedford, \& Westport, 1995; Kahn \& Antonucci, 1982). In addition, while some social relationships are consistent in patterns and quality, the patterns and quality of most social relationships change over time (Blieszner, Bedford, \& Westport, 1995). Accordingly, the convoy model proposes that each individual's social relationships may change in quantity and quality based on that individual's changing social needs and roles (Antonucci, 2001).

Antonucci and Akiyama (1987) noted that convoy model concepts include interpersonal and intrapersonal aspects of social relationships, where differences in age and gender might contribute to social relationships and behaviors. The inter-individual aspect of social relationships refers to the social relationships between individuals developing over time, whereas the intra-individual aspect refers to changes that take place within an individual over time. Similarly, Blieszner, Bedford, and Westport (1995) explained social relationships in terms of inter-individual and intra-individual aspects. In terms of the inter-individual aspect, people's social relationships are evolving, developing, and changing with the individual's development over time. With respect to the intra-individual perspective, social relationship changes are related to the changes in each individual's personal and social resources (e.g., health, age, and social contexts). 
With the convoy model, family and friends are important for social interaction and support in later life (Antonucci \& Akiyama, 1995). Each individual's close relationships may change based on their changing social needs and roles (Antonucci, 2001). Contact with family and friends may facilitate exchange of emotional support and improve quality of life for older adults (Antonucci, 2001). Therefore, the convoy model will support the hypothesis that engagement with family and friends may foster a greater level of resilience to widowhood.

\section{LITERATURE REVIEW}

\section{Widowhood and close social relationships}

There is increasing consensus that close relationships with family and friends provide psychological and social benefits for older widows. Frequent engagement with family and friends offers opportunities for broader social interactions and associations with other people (Duay \& Bryan, 2006), which provide for the developmental needs for resilience. With a sample of 4,130 older adults' ages 53 to 79 years, Hierarchical Linear Modeling (HLM) in Pinquart's 2003 study revealed that adult children, siblings, and close friends were specifically important for older widows. In addition, Pinquart found that relationships with family and friends provide benefits (e.g., reduce loneliness and increase emotional satisfaction) in later life that might foster resilience to widowhood.

Within the body of research of widowhood in later life, Elwert and Christakis (2006) stressed changes in relationships with adult children following widowhood - i.e., relationships with adult children intensify with widowhood. The volume of interaction with adult children increases and persists at higher level for widows. Mother and daughter dyads are typically closer than any other combination, with more daughters acting as confidantes and fewer likely to disappoint their mothers (Mottram \& Hortaçsu, 2005).

While studies have suggested that children are the most frequent providers of social and emotional support for older widows (Hooyman \& Kiyak, 2010), researchers recently have emphasized the importance of social relationships to positive adaptation by older widows (Karen et al., 2007). Researchers have emphasized that greater involvement in friendships during the first years of widowhood compensated for a spouse's absence for older widows (Benjamin et al., 2007). Boden-Albala et al. (2005) noted that face-to-face contact and residential proximity are important factors to close relationships in later life widowhood. According to Lopata (1996), many urban widowed women were happier if they had strong friendships that expanded their social lives and increased opportunities for being involved in social relationships. Consistent with previous research, Blieszner (2006) found that maintaining contact with family members, friends and neighbors is strongly associated with well-being and effective coping.

The fact that widowhood in later life encompasses diverse relationship changes makes it important to understand how older widows perceive their lives with regard to their social relationships (e.g., family, friends). This is important especially in view of the fact that more than 10 million Americans are older widows (Fields \& Casper, 2000). Given that social isolation may contribute to depression and loneliness (Stolzenberg \& Waite, 2005), it seems evident that close relationships with family and friends may improve resilience to widowhood.

Researchers found that older adults who engage frequently with family and friends have higher levels of self-efficacy and emotional resilience (McAuley et al., 2007). For example, Garcia, Banegas, Perez-Regadera, Cabrera, and Rodriguez-Artalejo (2005) discussed that family and friend relationships provide a sense of integration and serve as a predictor of self- 
rated well-being or quality of life after becoming a widow. In addition, Hooyman and Kiyak (2010) noted that being involved with family and friends has been known as an important benefit to the health of older widows because it alleviates depression and lends itself to day-today support. As such, engaging in family time and friendships seems likely to increase resilience among older widows (McAuley et al., 2007). In particular, Hooyman and Kiyak (2010) noted that active participation in activities (e.g., leisure, hobby, and day-to-day tasks) with family and friends after becoming widowed may reduce the possibility of disability and chronic disease. Clearly, frequent engagement with family and friends is a crucial factor for resilience to widowhood.

However, studying the impact of close relationships on resilience to widowhood has been largely neglected. Given the increasing population of older widows, more detailed research should be conducted to analyze the impact of close relationships on the quality of life of older widows. In fact, the sheer number of baby boomers continuing to age creates a level of urgency around this needed research. By understanding the associations, it is possible to set social policy and ultimately bolster the social support systems of older widows more effectively. Theoretically, older widows would be seeking ways to fill both the physical and emotional voids in their lives created by the loss of their partner. Therefore, the following hypotheses guided the design of the study:

H1: Older widows will report a higher quality of family relationships than married older adults.

H2: Older widows will report a higher quality of friendships than married older adults.

\section{METHODS}

\section{1. Procedures and Design}

The present study employed an explanatory approach using a cross-sectional study design. The study utilized data from the National Social Life, Health, and Aging Project (NSHAP, Waite et al., 2007) for the secondary data analysis. (NOTE: The funding Agency for the NSHAP was the United States Department of Health and Human Services). The NSHAP measured older adult health and other related social factors using a national scale for the purpose of assessing older adult well-being. Face-to-face interviews took place in participants' homes from 2005 to 2006.

\section{2. Participants and Measurement}

The unit of observation was community-dwelling adults 57-85 years of age $(n=3,005)$. The average age was 69 years old. Race/Ethnicity composition was $70 \%$ White, $17 \%$ Black, $10 \%$ Hispanic or non-Black, and $2 \%$ other ethnic groups. Gender composition was $48 \%$ male and $52 \%$ female.

\section{3. Independent variables}

Marital status was a nominal measurement (e.g., 1 = "married," 2 = "divorced," 3 = "widowed," and 4 = "never married"). 


\section{4. Dependent variables}

\section{4. 1. Family network size}

The size of family network was assessed with one question in this study: "How many relatives do you feel close to?" Family network size was calculated as an ordinal variable with scores on a 1-5 Likert type scale for the question ( $1=$ "one," $2=$ "2-3," $3=$ " $4-9$," $4=$ " $10-20$," and $5=$ "more than $20 ")$. The mean score of family size was $2.8(S D=1.2)$.

\section{4. 2. Quality of family relationships}

The quality of family relationships was assessed with two questions in this study: "How often can you open up to your family?" and "How often can you rely on your family?" Quality was calculated as an ordinal variable measuring frequency, with scores on a 1-3 Likert type scale for each question ( 1 = "hardly ever or never," 2 = "some of the time or seldom," and $3=$ "often"). The mean score of "opening up to family" was $2.2(S D=.9)$ and "relying on family" was $2.5(S D=.8)$. Alpha reliability for this sample was 0.86 .

\section{4. 3. Frequency of family demands/criticism}

Family demands and criticism were assessed with two questions in this study: "How often does your family make demands of you?" and "How often does your family criticize you?" Demands and criticism by family members were calculated as ordinal variables, with scores on a 1-3 Likert type scale for each question ( $1=$ "hardly ever or never," $2=$ "some of the time or seldom," and 3 = "often"). For this study, original scores $(1=$ "often," $2=$ "some of the time or seldom," and 3="hardly ever or never") to both questions were reversed from 1 to 3 to 3 to 1 so that a higher score indicates greater frequency. The mean score of family demands was 1.8 $(S D=0.8)$ and family criticism was $1.2(S D=0.7)$. Responses were summed with higher scores reflecting higher levels of demands and/or criticism. Alpha reliability for this sample was 0.82 .

\section{4. 4. Breadth of friendships}

The breadth of friendships was assessed with one question in this study: "How many friends do you have?" Breadth was calculated as an ordinal variable with scores on a 1-5 Likert type scale ( 1 = "one" 2 = "2-3", 3 = "4-9", $4=$ " $10-20 "$, and $5=$ "more than 20"). The mean score of breadth of friendships was $3.2(S D=1.4)$.

\section{4. 5. Quality of friendships}

Quality of friendships was assessed with two questions in this study: "How often can you open up to your friends?" and "How often can you rely on your friends?" Quality of friendships was calculated as an ordinal variable, with scores on 1-3 Likert type scale for each question (1 = "hardly ever or never," $2=$ "some of the time or seldom," and $3=$ "often"). The mean score of "opening up to friends" was $2.0(S D=0.9)$ and "relying on friends" was $2.2(S D=0.9)$. Alpha reliability for quality of friendships was 0.87 .

\section{4. 6. Frequency of demands/criticism by friends}

Demands and criticism from friends were assessed with two questions in this study: "How often do friends make demands of you?" and "How often do friends criticize you?" Demands and criticism from friends were measured as ordinal variables with scores on a 1-3 Likert type scale for each question $(1=$ "hardly ever or never," 2 = "some of the time seldom," and $3=$ "often"). 
For this study, the two questions' scores were reversed from 1 to 3 to 3 to 1 . Responses were summed with higher scores reflecting higher levels of demands and/or criticism. The mean score of demands made by friends was $1.0(S D=.7)$ and criticism from friends was 1.0 $(S D=0.7)$. Alpha reliability for demands and criticism from friends was 0.85 .

\subsection{Analysis}

To address the study's two hypotheses, multiple regression was performed to examine the degree of association between variables and how well the independent variables explained the dependent variable.

\section{RESULTS}

The descriptive statistics for the current study are summarized in Tables 1 and 2. The mean age of the sample was $69.3(S D=7.9)$ with a range from $57-85$ years. Forty-eight percent of the total sample $(n=3,005)$ was male and fifty-two percent was female. The race composition was $70 \%$ White, $17 \%$ African American, 10\% Hispanic, and $2.3 \%$ Other ethnicity. The quality of family relationships was regressed against marital status as summarized in Table 3.

Independent variables accounted for $4 \%$ of the variance in frequency of "opening up to family" $\left(R^{2}=.04, R^{2}\right.$ adjusted $\left.=.04, p<.001\right)$. Beta values indicated that participants who were widowed $(\beta=.05, p<.05)$ as opposed to married, had higher frequency of family opening up. On the other hand, independent variables accounted for $2 \%$ of the variance in frequency of respondents relying on family $\left(R^{2}=.02, R^{2}\right.$ adjusted $\left.=.02, p<.001\right)$. In addition, it was hypothesized that older widows would have a higher quality of friendships than older married adults.

With respect to quality of friendships, independent variables accounted for $5 \%$ of the variance in frequency of "opening up to friends" $\left(R^{2}=.05, R^{2}\right.$ adjusted $\left.=.04, p<.001\right)$. Beta values indicated that participants who were widowed $(\beta=.05, p<.05)$ as opposed to married, had a higher frequency of relying on friends.

Table 1. Descriptive Statistics $(n=3,005)$.

\begin{tabular}{|c|c|c|}
\hline Variables & Categories & Percentage \\
\hline \multirow{3}{*}{ Marital Status $(n=3,005)$} & Married & $62 \%$ \\
& Divorced & $12 \%$ \\
& Widowed & $22 \%$ \\
& Never married & $4 \%$ \\
\hline & & $63 \%$ \\
\hline Retirement Status & Retired & $37 \%$ \\
\hline$(n=3,005)$ & Non-retired & \\
\hline & & $70 \%$ \\
\hline Age $(n=3,005)$ & Young-old $(57-74)$ & \\
\hline & Middle-old $(75-85)$ & \\
\hline
\end{tabular}




\begin{tabular}{|c|c|c|}
\hline \multirow{3}{*}{ Ethnicity $(n=2,993)$} & White & $70 \%$ \\
& Black & $17 \%$ \\
& Hispanic & $10 \%$ \\
& Other Ethnicity & \\
\hline & & $4 \% \%$ \\
\hline \multirow{2}{*}{ Gender $(n=3,005)$} & Male & $52 \%$ \\
\hline \multirow{3}{*}{ Health status $(n=2,993)$} & Female & \\
& & $8 \%$ \\
& Poor & $19 \%$ \\
& Fair & $30 \%$ \\
& Gery good & $12 \%$ \\
\hline \multirow{2}{*}{ Income Status $(n=2,362)$} & Excellent & \\
& & $9 \%$ \\
& Far below average & $18 \%$ \\
& Below average & $33 \%$ \\
& Average & $16 \%$ \\
& Far above average & $3 \%$ \\
\hline
\end{tabular}

Table 2. Descriptive Statistics of Variables.

\begin{tabular}{|c|c|c|}
\hline Variables & Mean & Std. Deviation \\
\hline Family network & 3.5 & 0.84 \\
\hline Friend network & 3.5 & 0.75 \\
\hline $\begin{array}{c}\text { Religious network } \\
\text { families }\end{array}$ & 3.3 & 2.1 \\
\hline HH income relative to American & 2.9 & 1.0 \\
\hline Self-rated physical health & 3.3 & 1.1 \\
\hline
\end{tabular}

Table 3. Regression Results of Family Network Quality.

\begin{tabular}{|c|c|c|c|c|c|c|c|}
\hline \multicolumn{2}{|c|}{} & \multicolumn{2}{|c|}{$\begin{array}{c}\text { Frequency of opening up to } \\
\text { family }(n=2,352)\end{array}$} & \multicolumn{3}{|c|}{$\begin{array}{c}\text { Frequency of relying on } \\
\text { family }(n=2,338)\end{array}$} \\
\cline { 3 - 8 } & B & $\begin{array}{c}\text { Std. } \\
\text { Error }\end{array}$ & Beta & B & $\begin{array}{c}\text { Std. } \\
\text { Error }\end{array}$ & Beta \\
\hline Marital status & Divorced & .06 & .06 & .02 & -.12 & .06 & -.05 \\
\hline
\end{tabular}




\begin{tabular}{|c|c|c|c|c|c|c|c|}
\hline & Widowed & .12 & .05 & $.05 *$ & .03 & .05 & $.01^{*}$ \\
\cline { 2 - 8 } & Never married & -.20 & .10 & -.04 & -.37 & .10 & $\begin{array}{c}-.08^{* *} \\
*\end{array}$ \\
\hline
\end{tabular}

(Note. Frequency of opening up to family total $R^{2}=.044$, Frequency of relying on family total $R^{2}=.021, p<.001$, $* p<.05 * * \quad p<.01 * * * p<.001$. Reference group is older married adult group).

Table 4. Regression Results of Friend Network Quality.

\begin{tabular}{|c|c|c|c|c|c|c|c|}
\hline \multicolumn{2}{|c|}{} & \multicolumn{2}{|c|}{$\begin{array}{c}\text { Frequency of opening up to } \\
\text { friends }(n=2,346)\end{array}$} & \multicolumn{3}{c|}{$\begin{array}{c}\text { Frequency of relying on } \\
\text { friends }(n=2,272)\end{array}$} \\
\cline { 3 - 8 } & B & $\begin{array}{c}\text { Std. } \\
\text { Error }\end{array}$ & Beta & B & $\begin{array}{c}\text { Std. } \\
\text { Error }\end{array}$ & Beta \\
\hline \multirow{4}{*}{ Marital status } & Divorced & .10 & .06 & .04 & .02 & .06 & .01 \\
\cline { 2 - 8 } & Widowed & .02 & .06 & .01 & .11 & .05 & $.05^{*}$ \\
\cline { 2 - 8 } & Never married & .02 & .11 & .00 & -.10 & .11 & -.02 \\
\hline
\end{tabular}

(Note. Frequency of opening up to friends total $R^{2}=.048$, Frequency of relying on friends total $R^{2}=.035, p<.001$, $* p<.05 * * p<.01 * * * p<.001$, Reference group is older married adult group).

\section{DISCUSSION AND CONCLUSIONS}

The current study examined reports that older widows enjoy a higher quality of close relationships with friends and family than older married adults. For example, Ha (2008) noted that there is an increased amount of support from family and friends when older adults become widowed.

Ha (2008) compared married and widowed groups of older adults and found that widows have less confidence but report higher levels of emotional support from their social relationships. For older widows, the loss of a spouse does not negatively affect family relationships; on the contrary, family support increases after the loss of a spouse. Clearly, family and friends are a key source of emotionally close relationships for older widows.

Given the increasing numbers of older widows expected in the future, the current findings warrant future research on the specific dynamics around how close relationships serve to foster resilience to widowhood and the associated implications for social policy. In addition, future research should direct more attention to the vulnerabilities of older widows and their different approaches to resiliency via social relationships.

\section{Limitations of the Research}

The method of self-reported interview may have affected this study negatively. The faceto-face interview has an inherent potential bias due to the fact that the data is self-reported. The nature of interview design also has limitations in its ability to conduct explanatory research, because the criteria for inferring cause-and-effect relationships are not as easily established as they are in true or quasi-experimental design. Reducing the possibilities of rival explanations is also more difficult with interviews compared to experimental design, as face-to-face interviews do not typically have the same level of randomization that hold extraneous variables constant. 


\section{Conclusions}

Descriptive and multiple regression analysis were used to examine close relationships with friends and family of older widows. The findings revealed that older widows have a higher quality of close relationships than older married adults. These findings suggest that social welfare programs and policies need to address older widows' overall well-being. By understanding the factors of resiliency to widowhood, family and gerontological researchers, family policy makers, and family welfare workers will be able to focus on the social programs which provide most benefits to older widows and their families, friends, and other close associations.

\section{References}

[1] Antonucci T. C., Akiyama H., Journal of Gerontology 42(5) (1995) 519-527.

[2] Antonucci T. C. (2001). Social relations: An examination of social networks, social support, and sense of control. Handbook of the Psychology of Aging (5th ed.). Birren, James E.; Schaie, K. Warner; San Diego, CA, US: Academic Press, 427-453.

[3] Benjamin S. A., Krause N., Liang J., Journals of Gerontology 62B(2) (2007) S90-S99.

[4] Bennet K. M., International Journal of Geriatric Psychiatry 20 (2005) 280-284.

[5] Blieszner R., Bedford V. H., Westport C.T. (1995). Handbook of aging and the family. Greenwood Press/Greenwood Publishing Group, 509.

[6] Blieszner R., Personal Relationships 13(1) (2006) 1-18.

[7] Boden-Albala B., Litwak, E., Elkind M. S. V., Neurology 64(11) (2005) 1888-1892.

[8] Duay D. L., Bryan V. C., Educational Gerontology 32 (2006) 423-445.

[9] Elwert F., Christakis N. A., American Sociological Review 71(1) (2006) 16-41.

[10] Fields J., Casper J. M. (2000). America's families and living arrangements. Retrieved March 9, 2003, from http://www.census.gov/prod/2001pubs/p20-537.pdf.

[11] Garcia E., Banegas J. R., Perez-Regadera A. G., Cabrera R. H., Rodriguex-Artalejo F., Quality of Life Research 14 (2005) 511-520.

[12] Ha J. W., Journal of Marriage and Family 70 (2008) 306-318.

[13] Hooyman N. R., Kiyak H. A. (2010). Social Gerontology:Multidisciplinary perspective. Pearson Education, Inc.

[14] Kahn R. L., Antonucci T. C. (1982). Applying social psychology to the aging process: Four examples. In: Psychology and the older adult: Challenges for training in the 1980s. Santos, John F.; VandenBos, Gary R.; Washington, DC, US: American Psychological Association, 207-223.

[15] Karen R. S., Mavandadi S., Sorkin D. H. (2007). Optimizing Social Relationships as a Resource for Health and Well-Being in Later Life. In: Handbook of Health Psychology and Aging. Aldwin, Carolyn M., Park, Crystal L., Spiro, \& Avron III, New York, NY, US: Guilford Press, 267-285.

[16] Lopata H. Z. (1996). Current widowhood: Myths \& realities (understanding families). SAGE Publications, Inc. Thousand Oaks, California. 
[17] McAuley E., Morries K. S., Motl R. W., Hu L., Konopack J. F., Elavsky S., Health Psychology 26(3) (2007) 375-380.

[18] Mottram S. A., Hortaçsu N., Journal of Aging Studies 19(4) (2005) 471-488.

[19] Pinquart M., Journal of Social and Personal Relationships 20 (2003) 31-53.

[20] Resnick B., Gwyther L., Roberto K. (2010).Resilience in Aging: Concept, Research and Outcomes. Springer New York. Dordrecht Heidelberg London.

[21] Sheykhi M. T., Social Indicators Research 78(2) (20106) 251-270.

[22] Stolzenberg R. M., Waite L. J. (2005). Effects of Marriage, divorce, and widowhood on health. In: Work, Family, Health, and Well-Being. Bianchi, Suzanne M.; Casper, Lynne M.; King, Berkowitz Rosalind (2005). Mahwah, NJ, US: Lawrence Erlbaum Associates Publishers, 361-377.

[23] U. S. Census Bereau. (2012). Population Estimates. Retrieved April 15, 2008 from http://www.census.gov/

[24] Utz R. L., Carr D., Ness R., Wortman C., The Gerontologist 42(4) (2002) 522-533. 